\title{
Tokamak Dust Particle Size and Surface Area Measurement
}

\author{
William J. Carmack, Galen R. Smolik, Robert A. Anderl, Robert J. Pawelko, and Patricia B. Hembree \\ Fusion Safety Program \\ Idaho National Engineering and Environmental Laboratory, (INEEL) \\ P.O. Box 1625 \\ Idaho Falls, Idaho 83415-3885 \\ (208) 526-7576 \\ wjc@inel.gov
}

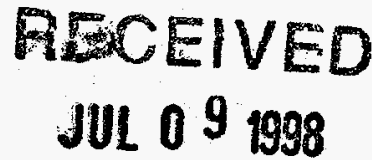

\section{ABSTRACT}

The INEEL has analyzed a variety of dust samples from experimental tokamaks: General Atomics' DIII-D, Massachusetts Institute of Technology's Alcator CMOD, and Princeton's TFTR. These dust samples were collected and analyzed because of the importance of dust to safety. The dust may contain tritium, be activated, be chemically toxic, and chemically reactive. The INEEL has carried out numerous characterization procedures on the samples yielding information useful both to tokamak designers and to safety researchers. Two different methods were used for particle characterization: optical microscopy (count based) and laser based volumetric diffraction (mass based). Surface area of the dust samples was measured using Brunauer, Emmett, and Teller, $\mathrm{BET}^{\mathrm{l}}$, a gas adsorption technique.

The purpose of this paper is to present the correlation between our particle size measurements and our surface area measurements for tokamak dust.

\section{INTRODUCTION}

A variety of dusts will be generated during the construction, maintenance, and operation activities associated with fusion energy production devices. Dust samples were collected from operating tokamak experiments and analyzed. Dust was collected by operations personnel at General Atomics' DIII-D, PPPL's TFTR, and MIT's Alcator CMOD experiments. The dust was characterized for composition, specific surface area, and particle size distribution by the INEEL Fusion Safety Program $^{2-4}$. The Fusion Safety Program is interested in dust generation in tokamaks primarily because of the potential for redistribution of the dust during both maintenance operations and during accident scenarios and the potential for chemical reactions with oxidizing environments during accident scenarios ${ }^{5}$. Redistribution of dust depends greatly upon the particle size distribution of the dust while the potential for reaction with oxidizing environments depends on the dust composition and the surface area available for reaction.
A number of different characteristic diameters can be calculated from a particle size distribution using either a "count based" or "mass based" method. One such diameter is the surface area mean diameter, $\mathrm{D}_{\mathrm{MVS}}$, also referred to as the mean volume-surface or the Sauter diameter. This diameter is useful in relating specific surface area of dust to the physical size distribution. We generally use count based methods of particle size distribution measurement and hence use the following relation to determine the $D_{\text {MVS }}$, $(\mu \mathrm{m})$.

$$
D_{M V S}=\frac{\sum_{i} n_{i} d_{i}^{3}}{\sum_{i} n_{i} d_{i}^{2}}
$$

where,

$\mathrm{n}_{\mathrm{i}}=$ number of particles in a distribution bin,

$\mathrm{d}_{\mathrm{i}}=$ midpoint diameter of bin, $\mu \mathrm{m}$.

For a monodisperse spherical powder, the specific surface area, $S\left(\mathrm{~m}^{2} / \mathrm{g}\right)$, is given by

$$
S=\frac{6}{\rho d}
$$

where,

$\mathrm{d}=$ diameter of monodisperse aerosol, $\mu \mathrm{m}$

$\rho=$ density, $\mathrm{kg} / \mathrm{m}^{3}$.

For a polydisperse powder, the specific surface area is given by Hinds ${ }^{6}$ :

$$
S=\frac{6}{\rho} \frac{d_{\mathrm{sa}}^{2}}{d_{m}^{3}}=\frac{6}{\rho D_{M V S}}
$$

where,

$\mathrm{d}_{\mathrm{s}}=$ diameter of average surface area, $\mu \mathrm{m}$

$\mathrm{d}_{\mathrm{m}}=$ diameter of average mass, $\mu \mathrm{m}$.

For the case where a polydisperse powder has an irregular shape, a general form of equation (2) is used:

$$
\mathrm{S}=\frac{\mathrm{k}}{\rho \mathrm{D}_{\mathrm{MVS}}} \text {. }
$$

where $\mathrm{k}$ is a surface area shape factor. Thus, for a sphere $\mathrm{k}$ $=6$. This $\mathrm{k}$-factor has been calculated for a number of 


\section{DISCLAMMER}

This report was prepared as an account of work sponsored by an agency of the United States Government. Neither the United States Government nor any agency thereof, nor any of their employees, makes any warranty, express or implied, or assumes any legal liability or responsibility for the accuracy, completeness, or usefulness of any information, apparatus, product, or process disclosed, or represents that its use would not infringe privately owned rights. Reference herein to any specific commercial product, process, or service by trade name, trademark, manufacturer, or otherwise does not necessarily constitute or imply its endorsement, recommendation, or favoring by the United States Government or any agency thereof. The views and opinions of authors expressed herein do not necessarily state or reflect those of the United States Government or any agency thereof. 


\section{DISCLAIMER}

Portions of this document may be illegible electronic image products. Images are produced from the best available original document. 
different geometrical shapes by German ${ }^{7}$, shown in Table 1. As the particle shape deviates from spherical, the $\mathrm{k}$ factor increases from the value of 6 . For a very large flake that is rather thin, the $\mathbf{k}$-factor is 24 , four times that of a sphere. Values for the $\mathbf{k}$-factor value for tokamak dusts can be determined using the results of particle size distribution measurements and BET specific surface area measurements of the dust.

Table 1. Surface Area Shape Factors (k-factors) for Different Shapes from German?

\begin{tabular}{|c|c|c|}
\hline Shape & Iral Ratu & N focor \\
\hline sphere & $1: 1: 1$ & 6.00 \\
\hline ellipsoid & $1: 2: 4$ & 7.57 \\
\hline cylinder & $1: 1: 1$ & 6.86 \\
\hline cylinder & $1: 1: 2$ & 7.21 \\
\hline cube & $1: 1: 1$ & 7.44 \\
\hline parallel-piped & $1: 4: 4$ & 9.38 \\
\hline flake & $1: 10: 10$ & 24.0 \\
\hline
\end{tabular}

Mean volume-surface diameters were determined from the particle size distribution measurement using equation 1. A mean volume-surface diameter has also been calculated from the total surface area measured by gas adsorption by using equation 3. Good agreement between the mean volume-surface diameter calculated using results of the particle size analysis and the mean volume-surface diameter determined from the surface area measurement indicates theoretically dense spherical particles. Significant differences indicate that the particles are not spherical, fully dense, or may actually represent a composite or agglomerate comprised of smaller primary particles. This is generally true for tokamak dust formed from graphitic materials.

\section{DISCUSSION}

We measured the specific surface area and the particle size distributions of several materials: stainless steel powder, aluminum powder, graphite powder, and dusts collected from three operating tokamaks. We presented details of our surface area measurements previously, obtained through the use of a Micromeritics ASAP 2010 Porosemitry Instrument ${ }^{4,8,9}$. The instrument uses a $\mathrm{Kr}$ or $\mathrm{N}_{2}$ gas adsorption method to measure specific surface area. Similarly, we have presented detailed particle size analysis methods and results in Carmack et al. ${ }^{2,3,4,10}$. We use two methods for particle size distribution measurements, optical microscopy and laser diffraction. We use a Nikon Optiphot 100 for optical microscopy and a Coulter LS130 for laser diffraction measurements.

Table 2 presents the $D_{M v s}$ results of non-tokamak dust based on measurements of specific surface area and particle size distribution measurements. Table 3 presents the results of particle size and specific surface area measurements for various tokamak dusts.

The ratio of the $D_{M v s}$ calculated from particle size distribution measurements to the $\mathrm{D}_{\mathrm{Mvs}}$ calculated based on specific surface area measurements is given in the last column of Tables 2 and 3. We do not refer to this ratio as a $\mathrm{k}$-factor, as in Table 1 , because we believe there is a significant amount of surface area due to surface connected porosity in many of the materials collected from tokamaks. We prefer to use the ratio to indicate the available surface area rather than a strict deviation from spherical dense material. The large ratios found in tokamak dust are generally due to the flake shape of the dust combined with surface connected porosity.

Figure 1 shows a graph of specific surface area plotted verses the $D_{M v s}$ for various steel and aluminum powders. Also shown in Figure 1 is BET specific surface area as a function of $\mathrm{D}_{\mathrm{MVS}}$ for theoretically dense, spherical steel and aluminum. Figure 2 shows a similar graph of the theoretically dense, spherical graphite and various graphite powders, TFTR dust, DIII-D dust, and Alcator CMOD dust measurements. As can be seen in Figures 1 and 2, all of the graphite measurements lie above the calculated theoretically dense, spherical surface area. Also seen in the graphs, all of the metallic powders with spherical shape (steels and aluminum), agree with the corresponding calculated theoretically dense, spherical particle surface areas.

The metallic dusts that we have analyzed are generally spherical with theoretical density. Our measurements show that the particle sizes measured with a count based method are comparable with the size calculated from surface area measurements using equation 3 . Our measurements of metallic dusts show that the dusts are generally spherical and have theoretical density. Deviations in either of these is apparent to some degree in Figures 1 and 2, and that deviation is due to the fact that the dusts contain large particles with some satelites and therefore are not strictly spherical.

The graphitic dusts that we have investigated all have measured specific surface areas greater than predicted by the particle size measurements. We believe that this is primarily due to the multi-faceted nature of graphite in addition to suspected surface connected porosity of the graphitic dusts. The Alcator CMOD dust analyzed for this study is primary composed of non-metallic components, primarily boron compounds. We expect future studies of CMOD dust to show metallic behavior. 


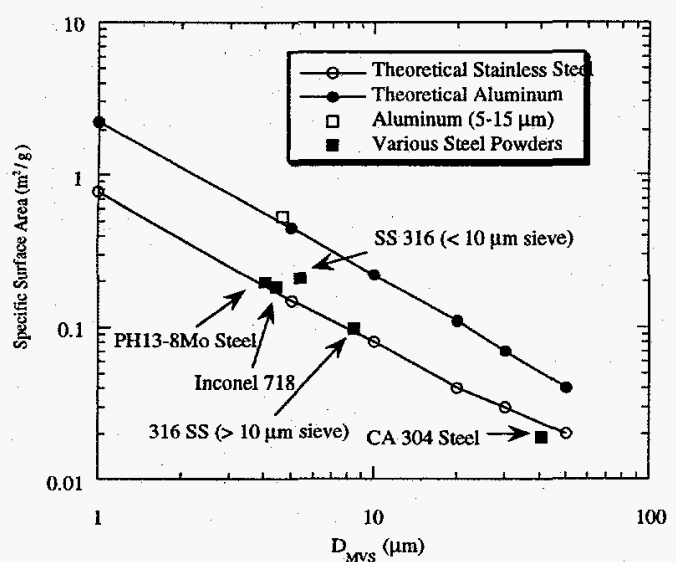

Figure 1. Specific Surface Area verses $D_{M v S}$ for various metallic powders.

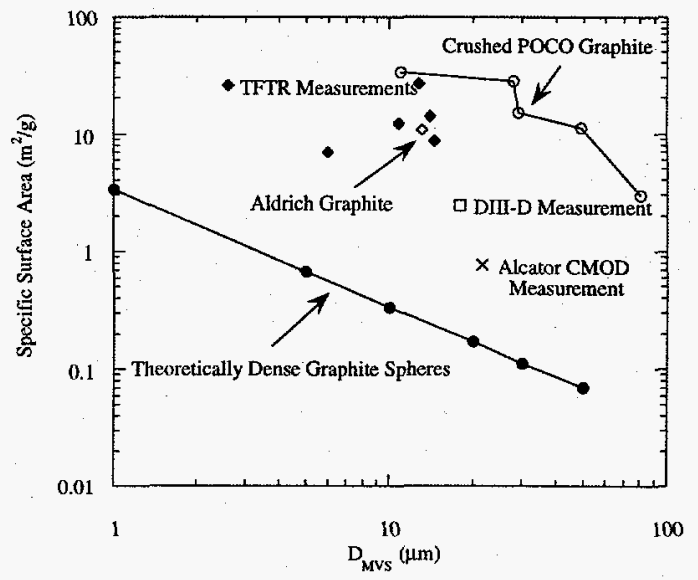

Figure 2. Specific surface area verses $D_{M v s}$ for various graphite powders and tokamak dusts.

Table 2. Specific surface area and particle size distribution measurement results.

\begin{tabular}{|c|c|c|c|c|c|}
\hline Material & $\begin{array}{c}D_{i n s}(\mu m) \\
(a)\end{array}$ & $\begin{array}{c}\text { Specilic Suthace } \\
\text { Area }\left(\mathbf{m}^{2} / g\right)\end{array}$ & $\begin{array}{l}\text { Densig: } \\
\left(\mathrm{kg} \cdot \mathrm{m}^{3}\right)\end{array}$ & $\frac{D_{\text {ins }}(\text { (Im) }}{(b)}$ & $\begin{array}{l}\text { Ratio } \\
\text { (a)(b) } \\
\end{array}$ \\
\hline Crushed POCO & 11.0 & 33.2 & 1800 & 0.10 & 109 \\
\hline Graphite & 28.0 & 28.1 & 1800 & 0.12 & 236 \\
\hline & 29.3 & 15.3 & 1800 & 0.22 & 133 \\
\hline & 49.3 & 11.23 & 1800 & 0.30 & 166 \\
\hline & 80.3 & 2.96 & 1800 & 1.13 & 71 \\
\hline CA 304 Stainless Steel & 40.7 & 0.02 & 7830 & 46.2 & 0.88 \\
\hline 718 Inconel & 4.4 & 0.183 & 7830 & 4.68 & 0.94 \\
\hline $316 \mathrm{SS}(<10 \mu \mathrm{m}$ sieve $)$ & 5.36 & 0.213 & 7830 & 4.03 & 1.3 \\
\hline $316 \mathrm{SS}(<10 \mu \mathrm{m}$ sieve $)$ & 8.42 & 0.098 & 7830 & 8.72 & 0.97 \\
\hline $\mathrm{Al}(5-15 \mu \mathrm{m}$ sieve $)$ & 4.65 & 0.532 & 2690 & 4.19 & 1.1 \\
\hline Aldrich Graphite & 13.1 & 10.90 & 1800 & 0.31 & 43 \\
\hline PH13-8Mo Steel & 4.0 & 0.198 & 7830 & 4.33 & 0.92 \\
\hline
\end{tabular}

(a) $\mathrm{D}_{\mathrm{MVS}}$ determined from particle size distribution measurement.

(b) $\mathrm{D}_{\mathrm{MvS}}$ determined from specific surface area measurement using equation (3).

(a)/(b) Ratio of particle size $D_{M v s}$ to specific surface area $D_{\text {MVs }}$.

Table 3. Tokamak Dust Measurements.

\begin{tabular}{|c|c|c|c|c|c|}
\hline Material & $\begin{array}{c}D_{\text {mis }}(\mathrm{mm}) \\
(\mathrm{a})\end{array}$ & $\begin{array}{c}\text { Specific Surface } \\
\text { Area }\left(\mathrm{m}^{2} / \mathrm{g}\right)\end{array}$ & $\begin{array}{c}\text { Density } \\
\left(\mathrm{kg} / \mathrm{m}^{3}\right)\end{array}$ & $\begin{array}{c}\mathrm{D}_{\mathrm{Mv}}(\mathrm{\mu m}) \\
(\mathrm{b})\end{array}$ & $\begin{array}{c}\text { Ratio } \\
(\mathrm{a})(\mathrm{b})\end{array}$ \\
\hline TFTR MIRI Window \#2 & 6.0 & 6.9 & 1800 & 0.48 & 12 \\
\hline TFTR MIRI Window \#4 & 14.6 & 8.7 & 1800 & 0.38 & 38 \\
\hline TFTR MIRI Window \#6 & 12.8 & 26.5 & 1800 & 0.13 & 102 \\
\hline TFTR MIRI Window \#8 & 10.8 & 12.3 & 1800 & 0.27 & 40 \\
\hline TFTR MIRI Window \#10 & 14.0 & 14 & 1800 & 0.24 & 59 \\
\hline Bottom of TFTR Vac. Vessel & 2.6 & 25.4 & 1800 & 0.13 & 20 \\
\hline DIII-D Dust & 18.0 & $2.44^{*}$ & 1800 & 1.37 & 13 \\
\hline CMOD Dust & 21.7 & 0.77 & 2460 & 3.16 & 7 \\
\hline
\end{tabular}

(a) $\mathrm{D}_{\mathrm{MvS}}$ determined from particle size distribution measurement.

(b) $\mathrm{D}_{\mathrm{MVS}}$ determined from specific surface area measurement using equation (3).

(a)/(b) Ratio of particle size $D_{M v s}$ to specific surface area $D_{M v s}$.

* Value for non-metal component of dust collected from DIII-D. 
The following figures illustrate the above points. Figure 3 shows a photograph of stainless steel 316 particles manufactured by spray atomization. Figure 4 shows a photomicrograph of Inconel-718 particles formed by a spray atomization process. The particles shown in Figures 3 and 4 show very spherical particles. The slight deviation between surface area measurements and particle size distribution measurements is attributed to the satellite attachment of small particles to large particles. This behavior has the effect of lowering the measured specific surface area while increasing the measured particle size.

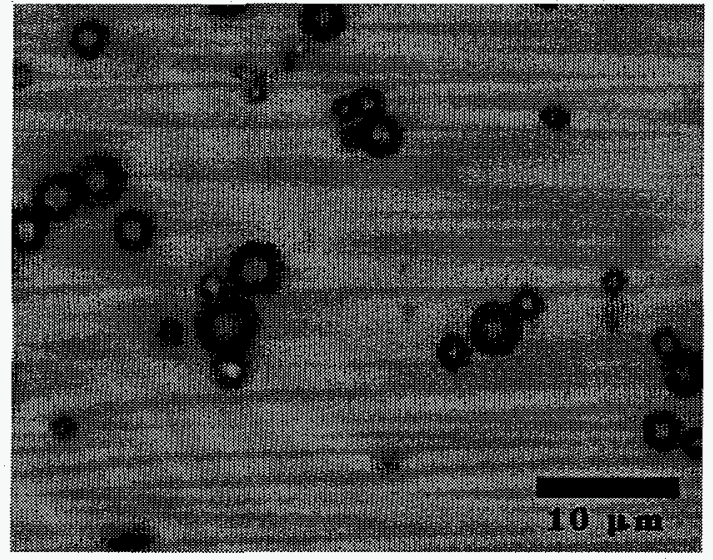

Figure 3. Photograph of stainless steel powder produced by spray atomization.

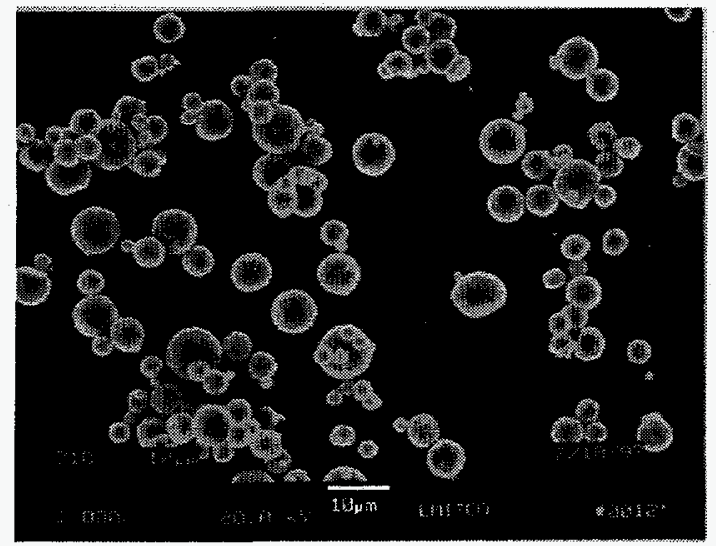

Figure 4. Photomicrograph of Inconel-718 steel particles.

Figure 5 shows a photograph of graphitic dust collected from the TFTR tokamak. Figure 6 shows a photograph of graphitic dust collected from the DIII-D tokamak. Figures 5 and 6 show graphitic flakes found in the TFTR and DIII-D vacuum vessels. The flakes are multi-faceted. This causes the particle size measurements to predict lower particle sizes yet surface area measurements are larger, yielding behavior shown in Figure 2 .

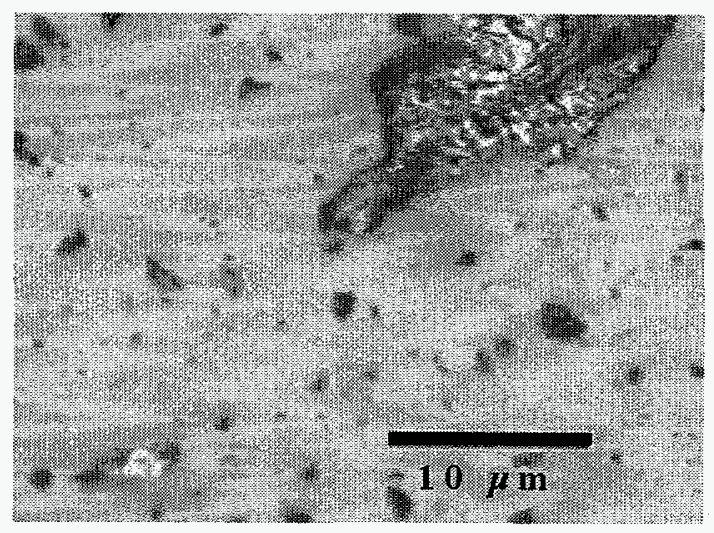

Figure 5. Photograph of graphitic flake particles collected from the TFTR vacuum vessel.

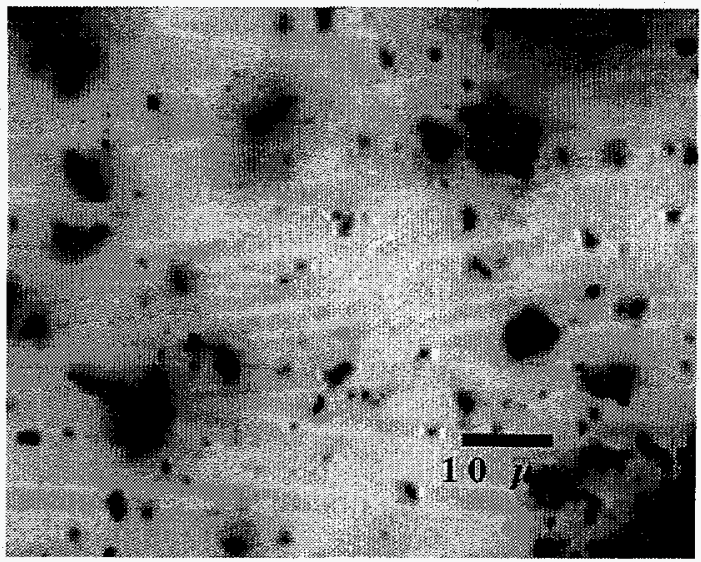

Figure 6. Photograph of graphitic flake particles collected from the DIII-D vacuum vessel.

Our measurements of both tokamak dust and various powders show the importance of accurate representation of surface area available for chemical reaction. Surface area, particularly of non-metallic dust should be obtained from measurement of specific surface area, rather than determined from particle size distribution measurement and assumed shape factors. A good discussion on the topic of chemical reactive of dust materials and the importance of accurate surface area measurements is found in Anderl et al ${ }^{12,13}$.

\section{CONCLUSIONS}

All of the graphite based materials had measured specific surface area significantly higher than theoretical dense, spherical material. We believe this is due to the multi-faceted nature of graphite flakes and the surfaceconnected porosity of graphite. Both of these characteristics would lead to significantly higher specific surface area measurements. The metallic materials yielded measurements consistent with theoretically dense, spherical particulate material. We believe this is due primarily to the method of manufacture, spray atomization ${ }^{11}$. Spray 
atomization typically yields a distribution of primarily spherical particulate with theoretical density. Spherical metallic particles have been observed throughout recently collected dust samples from Alcator CMOD.

Future work will focus on detailed measurement of surface area and particle size distributions of tokamak dust recently collected from the Alcator CMOD vacuum vessel and soon to be collected from the DIII-D vacuum vessel. The data shown here for DIII-D and CMOD represents a small sampling of the dust found inside the machines.

\section{ACKNOWLEDGMENTS}

This report is an account of work assigned to the U.S. Home Team under Task Agreement No. S 81 TT 08 within the Agreement among the European Atomic Energy Community, the Government of Japan, the Government of the Russian Federation, and the Government of the United States of America on Cooperation in the Engineering Design Activities for the International Thermonuclear Experimental Reactor ("ITER EDA Agreement") under the auspices of the International Atomic Agency (IAEA). The report has not been reviewed by the ITER Publications Office.

Prepared for the U.S. Department of Energy, Office of Fusion Energy, DOE Idaho Operations Office, Contract DE-AC07-94ID13223.

\section{REFERENCES}

1. S. Brunauer, P.H. Emmett, and E. Teller. Journal of the American Chemical Society, 60, (1938), p.309.

2. W. J. Carmack, M. E. Engelhardt, P. B. Hembree, K. A. McCarthy, and D. A. Petti. "DIII-D Dust Particulate Characterization". INEEL External Report \# INEELEXT-97-00702. November 1997.

3. W. J. Carmack, R. A. Anderl, G. R. Smolik, M. E. Engelhardt, R. J. Pawelko, S. V. Gorman, and P. B. Hembre. "Analysis and Characterization of TFTR Tokamak Dust", ITER EDF \# ITER/US/98/TE/SA-8. April 30, 1998.

4. S. V. Gorman, W. J. Carmack, and P. B. Hembree. "CMOD Dust Particulate Characterization". INEEL ITER EDF \# ITER/US/97/TE/SA-17. August 1997.
5. K. A. McCarthy, D. A. Petti, W. J. Carmack, and G. R. Smolik, "The Safety Implications of Tokamak Dust Size and Surface Area." presented at the Fourth International Symposium on Fusion Nuclear Technology, Tokyo, Japan, April 6-11, 1997, to be published in Fusion Engineering and Design.

6. W. C. Hinds. Aerosol Technology, Properties, Behavior, and Measurement of Airborne Particles, p. 80. John Wiley and Sons. New York, NY. 1982.

7. R. M. German, Powder Metallurgy Science, p 41. Metal Powder Industries Federation, Princeton, NJ, 1984.

8. R. A. Anderl, G. R. Smolik, W. J. Carmack, P. B. Hembree, M. A. Oates, and R. J. Pawelko. "BET Surface Area Measurements of Materials for Fusion Safety Studies". ITER EDF \# ITER/US/97/TE/SA20. January, 1998.

9. G. R. Smolik, R. A. Anderl, R. J. Pawelko, W. J. Carmack, P. B. Hembree, and M. A. Oates. "BET Surface Area Measurements of Materials for Fusion Safety Studies". 17th IEEE/NPSS Symposium on Fusion Engineering. San Diego, CA Oct. 6-7, 1997

10. W. J. Carmack, K. A. McCarthy, D. A. Petti, C. P. C. Wong, and A. G. Kellman. "Collection and Analysis of Particulate from the DIII-D Tokamak". presented at the Fourth International Symposium on Fusion Nuclear Technology, Tokyo, Japan, April 611, 1997, to be published in Fusion Engineering and Design.

11. A. J. Yule and J. J. Dunkley, Atomization of Melts for Powder Production and Spray Deposition, pp 165175, Clarendon Press, Oxford, UK, 1994.

12. R. A. Anderl, R. J. Pawelko, G. R. Smolik, and R. G. Castro, "Chemical Reactivity of Plasma Sprayed Beryllium" 13th Topical Meeting, Technology of Fusion Energy, Nashville, TN. June 7-11, 1998.

13. R. A. Anderl, "Steam Chemical Reactivity Experiments for Iradiated-Annealed Beryllium" ITER/US/98/TE/SA-1, March 5, 1998. 